\title{
Qualidade de mudas de moringa sob diferentes níveis de nutrientes aplicados via fertirrigação
}

Kleane Targino Oliveira Pereira ${ }^{1}$, Francisco de Assis de Oliveira ${ }^{1 *}$, Antonio Lucieudo Gonçalves Cavalcante ${ }^{1}$, Renata de Paiva Dantas ${ }^{1}$, Mychelle Karla Teixeira de Oliveira ${ }^{1}$, Jessilanne Plínia Barbosa de Medeiros Costa ${ }^{1}$

${ }^{1}$ Universidade Federal de Rural do Semi-Árido, Av. Francisco Mota, 572, Costa e Silva, CEP 59625-900, Mossoró, RN, Brasil

*Autor correspondente:

thikaoamigao@ufersa.edu.br

Termos para indexação:

Moringa oleifera

Nutrição vegetal

Silvicultura

Index terms:

Moringa oleifera

Plant nutrition

Silviculture

Histórico do artigo:

Recebido em 14/09/2015

Aprovado em 16/12/2016

Publicado em 30/12/2016

doi: 10.4336/2016.pfb.36.88.1038
Resumo - O objetivo do presente trabalho foi avaliar a qualidade de mudas de moringa em função da posição das sementes no fruto e da concentração de nutrientes na solução de fertirrigação. Realizou-se um experimento seguindo o delineamento inteiramente casualizado, com os tratamentos arranjados em esquema fatorial $3 \times 4$, sendo três posições de sementes no fruto (basal, mediana e apical) e quatro doses de nutrientes $(0$, 50,100 e $150 \%$ da dose padrão), com quatro repetições. Foram avaliados os seguintes parâmetros: altura (ALT), diâmetro do coleto (DC), número de folhas, matéria seca da parte aérea (MSPA), matéria seca do sistema radicular (MSSR) e matéria seca total, relação ALT/DC, MSPA/MSSR e índice de qualidade de Dickson. Os dados foram submetidos à análise de variância pelo teste $\mathrm{F}$ e as médias comparadas pelo teste de Tukey a 5\% de probabilidade, para o efeito da posição da semente no fruto; e por análise de regressão, para os dados provenientes de níveis de nutrientes. A posição da semente no fruto não influenciou o vigor das mudas. Recomenda-se a solução de fertirrigação utilizando-se concentração de nutrientes variando de 80 a $100 \%$ da solução padrão adotada, para as condições deste experimento.

\section{Quality of seedlings of Moringa oleifera under different levels of nutrients applied via fertigation}

\begin{abstract}
The objective of the present work was to evaluate the quality of seedlings of Moringa oleifera Lam. according to seeds position in the fruit and the concentration of nutrients in the fertigation solution. An experiment was carried out following entirely randomized design, with treatments arranged in a factorial scheme $3 \times 4$, in which the factors were three positions of seeds in the fruit (basal, medium and apical) and four doses of nutrients $(0,50,100$ and $150 \%$ of the standard dose), with four replications. The following parameters were evaluated: height $(\mathrm{H})$, collar diameter $(\mathrm{CD})$, leaf number, aerial dry mass (ADM), dry mass of the root system (DMRS), total dry mass, $\mathrm{H} / \mathrm{CD}$ ratio, $\mathrm{ADM} / \mathrm{DMRS}$ ratio and Dickson quality index. Data of the effect of seeds position in the fruit were submitted to analysis of variance with test $F$ and comparison of means by Tukey's test at 5\% of probability, while data of nutrients levels was submitted to regression analysis. Seeds position in the fruit did not influence seedlings vigor. Fertigation solution with nutrients concentration varying between 80 and $100 \%$ of considered standard solution is recommended for similar conditions of this experiment.
\end{abstract}




\section{Introdução}

Moringa oleifera (Moringaceae), conhecida popularmente por lírio branco, quiabo de quina, acáciabranca, árvore rabanete de cavalo e cedro, é uma planta arbórea que chega até $8 \mathrm{~m}$ de altura. A planta possui uma variedade de aplicações, sendo chamada por muitos de planta multiuso, inclusive para a alimentação humana, devido à sua composição rica em vitaminas e sais minerais (Jesus et al., 2013).

De acordo com Ferreira et al. (2008), a moringa apresenta excelentes propriedades nutricionais, podendo ser uma alternativa ao consumo de sementes leguminosas, como fonte de proteínas de alta qualidade, de óleo e de compostos antioxidantes. Além disso, suas sementes apresentam propriedade coagulante, com potencial para serem utilizadas no tratamento de água (Pritchard et al., 2010; Sánchez-Martín et al., 2010; Lo Monaco et al., 2013).

A produção de mudas de qualidade é fator chave para obtenção do êxito para o estabelecimento de bons povoamentos florestais, e a qualidade da muda está diretamente relacionada com a escolha da semente, inclusive quanto à posição das mesmas na planta e/ ou no fruto, pois, conforme Marcos Filho (2005), as sementes localizadas na base dos frutos estão mais próximas da fonte fotossintética, podendo apresentar maior acúmulo de reservas e, por esse motivo, gerar plantas mais desenvolvidas.

$\mathrm{Na}$ literatura existem poucos estudos nesta temática com sementes de moringa, a exemplo do estudo realizado por Oliveira et al. (2013), os quais constataram que as sementes provenientes da posição basal ou apical originaram mudas mais vigorosas que as sementes localizadas na porção mediana. Além disso, esses autores verificaram que plantas provenientes de sementes da posição basal são mais sensíveis à salinidade.

Oliveira \& Morais (1997) avaliaram a influência da posição da semente em frutos sobre a germinação e desenvolvimento inicial de leucena (Leucaena leucocephala (Lam.) de Wit) e algarobeira (Prosopis juliflora (SW.) DC.), e constataram que a posição da semente influenciou a germinação e os teores de nutrientes nas duas espécies, mas não afetou o desenvolvimento das plantas.

O efeito da nutrição mineral sobre o desenvolvimento foliar é muito importante, pois as folhas são órgãos vegetais responsáveis pela captação de energia solar e pela produção de material orgânico através da fotossíntese (Bernardi et al., 2000).

A aplicação de fertilizantes via água de irrigação, denominada fertirrigação, é uma técnica de grande aplicabilidade na agricultura nacional, principalmente na produção de frutas e hortaliças. No entanto, a literatura atual é escassa no que diz respeito ao uso desta tecnologia na produção de mudas de espécies arbóreas.

Tucci et al. (2011) avaliaram o efeito de doses de nitrogênio, fósforo e potássio sobre o crescimento de mudas de mogno (Swietenia macrophylla) e não observaram resposta significativa. Sarzi et al. (2010) avaliaram mudas de ipê-amarelo-cascudo (Tabebula chrysotricha Standl.) produzidas em diferentes substratos e soluções de fertirrigação, variando de 50 a $200 \%$ da concentração de fertilizantes utilizada por viveiristas da região de Ibaté, SP (concentração da solução padrão, para $100 \mathrm{~L}$ de água: $42,6 \mathrm{~g}$ de nitrato de cálcio, $5 \mathrm{~g}$ de cloreto de potássio, $50 \mathrm{~g}$ de sulfato de amônio e $32,6 \mathrm{~g}$ de sulfato de magnésio), e não observaram diferença significativa entre as soluções, recomendando, assim, fertirrigação com solução de nutrientes correspondentes a $50 \%$ da solução padrão.

Verifica-se a necessidade de mais estudos sobre o manejo da adubação na produção de mudas e a escolha da posição da semente no fruto. Diante da importância desta espécie para a região e da carência de estudos nesta temática, este trabalho foi desenvolvido com o objetivo de avaliar o efeito de diferentes concentrações de nutrientes aplicadas via fertirrigação e a posição das sementes no fruto na formação de mudas de moringa.

\section{Material e métodos}

O experimento foi realizado de março a maio de 2013, em casa de vegetação, no Departamento de Ciências Ambientais e Tecnológicas da Universidade Federal Rural do Semi-Árido (UFERSA), em Mossoró, RN (5'11'31''S e $37^{\circ} 20^{\prime} 40^{\prime} \mathrm{W}$, altitude média de $18 \mathrm{~m}$ ). A casa de vegetação utilizada apresenta as dimensões de $7 \mathrm{~m}$ de largura com $18 \mathrm{~m}$ de comprimento, construída com estrutura de aço galvanizado. A cobertura é do tipo túnel, feita com filme agrícola com polietileno de baixa densidade e transparente, com $150 \mu \mathrm{m}$ de espessura e tratamento anti-ultravioleta. As paredes laterais e frontais são confeccionadas com sombrite com $50 \%$ de sombreamento. 
De acordo com a classificação de Köppen, o clima da região é seco e muito quente, com duas estações pouco definidas: uma seca (junho a janeiro) e outra chuvosa (fevereiro a maio). A temperatura média anual é de $27^{\circ} \mathrm{C}$, a umidade relativa do ar é de $68 \%$ e a precipitação pluviométrica anual é bastante irregular, com média de $673 \mathrm{~mm}$.

O delineamento experimental utilizado foi inteiramente casualizado, em esquema fatorial $3 \times 4$, com quatro repetições, sendo a unidade experimental representada por um vaso contendo $3 \mathrm{dm}^{3}$ de substrato.

Os tratamentos resultaram da combinação de quatro dosagens de fertilizantes aplicados via fertirrigação $(0$, 50,100 e $150 \%$ ) com três posições das sementes no fruto (basal, mediana e apical). Na dose zero ( $0 \%$ ) as mudas eram irrigadas com água do sistema de abastecimento da UFERSA. A concentração 100\% correspondeu à solução padrão com as seguintes quantidades de fertilizantes adicionados à água $\left(\mathrm{g} \mathrm{L}^{-1}\right): 0,5 ; 0,37 ; 0,14$ e 0,27 de nitrato de cálcio $(15 \% \mathrm{~N} ; 20 \% \mathrm{Ca})$, nitrato de potássio $(13 \% \mathrm{~N} ; 44 \% \mathrm{~K})$, fosfato monoamônico $(52 \% \mathrm{P} ; 10 \% \mathrm{~N})$, sulfato de magnésio $(12 \% \mathrm{~S} ; 9,5 \%$ $\mathrm{Mg}$ ), respectivamente, e como fonte de micronutrientes adicionou-se 0,06 $\mathrm{g} \mathrm{L}^{-1}$ de Quelatec ${ }^{\circledR}$ (mistura sólida de EDTA-chelated nutrientes contendo $0,28 \% \mathrm{Cu}, 7,5 \% \mathrm{Fe}$, $3,5 \% \mathrm{Mn}, 0,7 \% \mathrm{Zn}, 0,65 \%$ B e $0,3 \% \mathrm{Mo}$ ).

A quantidade de solução aplicada em cada vaso variou conforme o desenvolvimento das plantas, aplicandose diariamente $50 \mathrm{~mL}$, do dia do desbaste aos 30 dias após a semeadura (DAS), e $100 \mathrm{~mL}$, de 30 DAS até o final do experimento (55 DAS). Desta forma, ao final do experimento foi aplicado o volume total de $4 \mathrm{~L}$ por planta, resultando no total, em $\mathrm{g}$ planta $^{-1}$, de: 0,$55 ; 0,29 ; 0,65 ; 0,40 ; 0,10$ e 0,13 , de N, P. K, Ca, Mg e $\mathrm{S}$, respectivamente. Para os micronutrientes foram aplicadas as seguintes quantidades $\left(\mathrm{mg} \mathrm{planta}^{-1}\right)$ : 0,67 ; 18,$0 ; 8,4 ; 1,68 ; 1,56$ e 0,72 , para $\mathrm{Cu}, \mathrm{Fe}, \mathrm{Mn}$. Zn, B e Mo, respectivamente.

Os vasos utilizados no experimento eram de concreto e tinham capacidade para $3,5 \mathrm{dm}^{3}$, nos quais foram colocados $3 \mathrm{dm}^{3}$ de substrato. Como substrato, foi utilizado solo classificado como Argissolo Vermelho Amarelo eutrófico e antes da instalação do experimento foi realizada análise química, de acordo com os métodos descritos por Claessen (1997), com as seguintes características: $\mathrm{P}$ melich-1, 5,33 mg dm${ }^{-3} ; \mathrm{MO}, 2,7 \mathrm{~g}$ $\mathrm{dm}^{-3} ; \mathrm{pH}$ em $\mathrm{H}_{2} \mathrm{O}, 6,18 ; \mathrm{K}^{+}, 0,44 \mathrm{mmol}_{\mathrm{c}} \mathrm{dm}^{-3} ; \mathrm{Ca}^{2+}$, $1,62 \mathrm{mmol}_{\mathrm{c}} \mathrm{dm}^{-3} ; \mathrm{Mg}^{2+}, 1,88 \mathrm{mmol}_{\mathrm{c}} \mathrm{dm}^{-3} ; \mathrm{H}+\mathrm{Al}, 1,32$ mmol $\mathrm{dm}^{-3}$, CTC a pH 7, 7,49 $\mathrm{mmol}_{\mathrm{c}} \mathrm{dm}^{-3}$ e saturação por bases $(\mathrm{V}), 73 \%$.

Os frutos de moringa (Moringa oleifera Lam) foram colhidos de uma planta localizada nas imediações do campus central da UFERSA $\left(05^{\circ} 12^{\prime} 07^{\prime \prime} \mathrm{S} ; 37^{\circ} 19^{\prime} 25^{\prime \prime} \mathrm{W}\right)$; as sementes foram separadas segundo sua posição no fruto (Figura 1). As primeiras sementes localizadas na porção apical e na porção basal (próximo ao pedúnculo) do fruto foram descartadas.

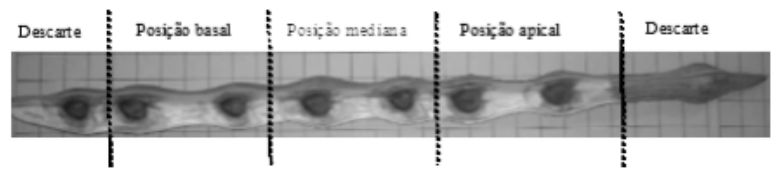

Figura 1. Esquematização adotada para a classificação dos frutos e coleta das sementes.

Foram semeadas quatro sementes em cada vaso, e o desbaste foi realizado aos 10 dias após a semeadura, deixando-se em cada vaso a plântula mais vigorosa.

As irrigações foram realizadas utilizando água do sistema de abastecimento do campus da UFERSA no período entre a semeadura e o desbaste. Após esse período, foram feitas fertirrigações diárias, de acordo com cada tratamento, com exceção da concentração $0 \%$, na qual as plantas receberam apenas água durante todo o experimento.

Ao longo do período experimental foram realizadas duas avaliações de crescimento, de forma não destrutiva ( 25 e 40 dias após a semeadura - DAS), avaliando-se os seguintes parâmetros: altura (ALT), medida do coleto ao meristema apical da planta com régua graduada $(\mathrm{mm})$; diâmetro do coleto (DC), utilizando um paquímetro digital (mm) e número de folhas (NF), por contagem. Aos 55 DAS, além dos parâmetros não destrutivos (ALT, DC e NF), as plantas foram coletadas e avaliadas de forma destrutiva, para análise dos parâmetros: matéria seca da parte aérea (MSPA), matéria seca do sistema radicular (MSSR) e matéria seca total (MST). A partir dos dados coletados foram feitas as correlações: ALT/ DC, MSPA/MSSR e calculado o índice de qualidade de Dickson (IQD).

Para a coleta dos dados de matéria seca, as plantas foram acondicionadas em sacos de papel devidamente identificados, que foram colocados em estufa de circulação de ar forçado a $65{ }^{\circ} \mathrm{C}$ até atingirem massa constante.

O IQD foi calculado utilizando-se as características morfológicas MST, MSPA, MSSR, ALT e DC (Dickson et al., 1960), usando a equação 1 . 


$$
\mathrm{IQD}=\frac{\mathrm{MST}}{\frac{\mathrm{ALT}}{\mathrm{DC}}+\frac{\mathrm{MSSR}}{\mathrm{MSPA}}}
$$

Onde: IQD = índice de qualidade de Dickson, $\mathrm{MST}=$ matéria seca total $(\mathrm{g}), \mathrm{ALT}=$ altura $(\mathrm{mm}), \mathrm{DC}=$ diâmetro do coleto $(\mathrm{mm})$, MSSR $=$ matéria seca de raízes $(\mathrm{g})$, $\mathrm{MSPA}=$ matéria seca da parte aérea $(\mathrm{g})$.

Os dados foram submetidos à análise de variância (teste F) e, quando detectados efeitos significativos da interação entre os fatores estudados, realizouse desdobramento dos fatores. O efeito das doses de fertirrigação foi analisado através de análise de regressão. O efeito das variáveis qualitativas (posições das sementes no fruto) foi analisado pelo teste Tukey ao nível de $5 \%$ de probabilidade. As análises estatísticas foram realizadas com o Software SISVAR (Ferreira, 2011).

\section{Resultados e discussão}

Não houve efeito significativo da interação entre os fatores posição de sementes no fruto e concentração de nutrientes na solução de fertirrigação para nenhum dos parâmetros analisados, bem como também não foi observada resposta significativa para o fator posição de sementes $(\mathrm{p}>0,05)$. No entanto, verificou-se resposta significativa para concentração de nutrientes em todos os parâmetros ao nível de significância de 1\% de probabilidade (Tabela 1).
A posição da semente no fruto não afetou o acúmulo de biomassa, obtendo-se entre as três posições valores médios de 4,98 $\mathrm{g}$ planta $^{-1}$ para MSPA, 2,46 g planta $^{-1}$ para MSSR e 7,43 $\mathrm{g}$ planta $^{-1}$ para MST. Também não houve diferença significativa para a relação ALT/DC, relação MSPA/MSR e IQD, sendo observados os valores médios de 5,11 (ALT/DC), 2,04 (MSPA/MSSR) e 1,64 (IQD) (Tabela 1). Esses resultados indicam que sementes oriundas de qualquer posição podem ser utilizadas para produção de mudas de moringa. Tal comportamento difere, em parte, dos resultados obtidos por Oliveira et al. (2013). Estes autores verificaram que sementes oriundas da posição mediana resultaram em mudas com menor número de folhas e altura, entretanto, também não observaram diferença significativa para diâmetro do coleto.

A posição da semente no fruto não afetou o acúmulo de biomassa, obtendo-se entre as três posições valores médios de 4,98 $\mathrm{g} \mathrm{planta}^{-1}$ para MSPA, 2,46 $\mathrm{g}_{\text {planta }}{ }^{-1}$ para MSSR e 7,43 $\mathrm{g}_{\text {planta }}{ }^{-1}$ para MST. Também não houve diferença significativa para a relação ALT/DC, relação MSPA/MSR e IQD, sendo observados os valores médios de 5,11 (ALT/DC), 2,04 (MSPA/MSSR) e 1,64 (IQD) (Tabela 1). Esses resultados indicam que sementes oriundas de qualquer posição podem ser utilizadas para produção de mudas de moringa. Tal comportamento difere, em parte, dos resultados obtidos por Oliveira et al. (2013), os quais verificaram que sementes oriundas da posição mediana resultaram em mudas com menor número de folhas e altura, entretanto, estes autores também não observaram diferença significativa para diâmetro do coleto.

Tabela 1. Valores médios de altura (ALT), diâmetro do coleto (DC), número de folhas (NF), matéria seca da parte aérea (MSPA), matéria seca do sistema radicular (MSSR), matéria seca total (MST), relação ALT/DC, relação MSPA/MSSR e índice de Dickson (IQD) em mudas de moringa (Moringa oleifera Lam.) obtidas de sementes oriundas de diferentes posições no fruto e fertirrigadas com diferentes concentrações de nutrientes.

\begin{tabular}{|c|c|c|c|c|c|c|c|c|c|}
\hline \multirow{2}{*}{$\begin{array}{l}\text { Posição das } \\
\text { sementes }\end{array}$} & \multicolumn{3}{|c|}{------- Altura (mm)-------- } & \multicolumn{3}{|c|}{-- Diâmetro do coleto $(\mathrm{mm})$-- } & \multicolumn{3}{|c|}{----- Número de folhas ------ } \\
\hline & 25 DAS & 40 DAS & 55 DAS & 25 DAS & 40 DAS & 55 DAS & 25 DAS & 40 DAS & 55 DAS \\
\hline & \multicolumn{3}{|c|}{--------- cm -------- } & \multicolumn{3}{|c|}{---------- mm --------- } & \multicolumn{3}{|c|}{--------- unidade ---------- } \\
\hline Apical & $24,42 \mathrm{a}$ & $39,08 \mathrm{a}$ & $56,52 \mathrm{a}$ & $5,38 \mathrm{a}$ & $7,79 \mathrm{a}$ & 9,18 a & $8 \mathrm{a}$ & $11 \mathrm{a}$ & $12 \mathrm{a}$ \\
\hline Mediana & $24,13 \mathrm{a}$ & $39,37 \mathrm{a}$ & $58,86 \mathrm{a}$ & $5,63 \mathrm{a}$ & $7,66 \mathrm{a}$ & $9,18 \mathrm{a}$ & $8 \mathrm{a}$ & $9 \mathrm{a}$ & $12 \mathrm{a}$ \\
\hline \multirow[t]{2}{*}{ Basal } & 23,46 a & $38,79 \mathrm{a}$ & 59,64 a & $5,72 \mathrm{a}$ & $7,51 \mathrm{a}$ & $9,57 \mathrm{a}$ & $8 \mathrm{a}$ & $9 \mathrm{a}$ & $13 \mathrm{a}$ \\
\hline & MSPA & MSSR & MST & & & ALT/DC & \multicolumn{2}{|c|}{ MSPA/MSSR } & IQD \\
\hline \multicolumn{10}{|c|}{ Posição da semente } \\
\hline \multicolumn{10}{|c|}{--_--- g planta ${ }^{-1}$} \\
\hline Apical & $5,05 \mathrm{a}$ & $2,54 \mathrm{a}$ & $7,59 \mathrm{a}$ & & & $5,02 \mathrm{a}$ & $1,99 \mathrm{a}$ & & $1,56 \mathrm{a}$ \\
\hline Mediana & $4,93 \mathrm{a}$ & $2,34 \mathrm{a}$ & $7,27 \mathrm{a}$ & & & $5,14 \mathrm{a}$ & $2,11 \mathrm{a}$ & & $1,65 \mathrm{a}$ \\
\hline Basal & $4,97 \mathrm{a}$ & $2,46 \mathrm{a}$ & $7,43 \mathrm{a}$ & & & $5,17 \mathrm{a}$ & $2,02 \mathrm{a}$ & & $1,71 \mathrm{a}$ \\
\hline
\end{tabular}

* Médias seguidas de mesma letra na coluna por parâmetro, não diferem entre si a 5\% de probabilidade, pelo teste de Tukey. DAS - Dias após a semeadura. 
Resultados semelhantes, onde a posição da semente no fruto não apresenta efeito significativo no desenvolvimento de plântulas, também foram observados para outras espécies, como sabiá (Mimosa caesalpiniifolia Benth) (Freitas et al., 2013), leucena (Leucaena leucocephala) e algaroba ((Prosopis juliflora) (Oliveira \& Morais, 1997).

Analisando o efeito das doses de nutrientes, verificase que, de forma geral, os dados obtidos para todos os parâmetros avaliados ajustaram em equações quadráticas (Figura 2).

Para a altura das mudas (ALT), os maiores valores foram obtidos nas doses referentes a $110 \%, 96 \%$ e $104 \%$ da solução padrão nas avaliações aos 25,40 e 55 DAS, com alturas máximas de $26,92 \mathrm{~cm}, 43,38 \mathrm{~cm}$ e $63,18 \mathrm{~cm}$, respectivamente. Comparando esses valores com os obtidos nas mudas em ausência de fertirrigação, verificaram-se aumentos de $44 \%$ aos 25 DAS, $38 \%$ aos 40 DAS e $28 \%$ aos 55 DAS (Figura 2A).

Apesar de os maiores valores da altura terem ocorrido para doses próximas de $100 \%$ da solução padrão (figura $2 \mathrm{~A})$, verificou-se pouco ganho em relação aos valores obtidos na dose de $50 \%$ (6\% aos 55 DAS, $7 \%$ aos 40 DAS e $10 \%$ aos 25 DAS), tendo também ocorrido pequena redução quando as mudas foram fertirrigadas com a dose de $150 \%$ ( $4 \%$ aos 55 DAS, $8 \%$ aos 40 DAS e $4 \%$ aos 25 DAS).

Cruz et al. (2006) avaliaram o efeito da adubação nitrogenada na produção de mudas de sete-cascas (Samaneai nopinata (Harms) Ducke) e verificaram que os dados de crescimento das mudas enquadraram-se em funções quadráticas, em função do aumento nas doses de nitrogênio.

O DC das mudas aumentou de acordo com o incremento de fertilizantes na solução de fertirrigação até as concentrações de $111 \%, 112 \%$ e $111 \%$, obtendo DC máximos de $6,2 \mathrm{~mm}, 8,4 \mathrm{~mm}$ e 10,3 mm, aos 25, 40 e 55 DAS, respectivamente (Figura 2B). Verificou-se, ainda, aumento no DC das mudas em comparação às mudas irrigadas apenas com água de aproximadamente $35 \%$ (25 DAS), 32\% (40 DAS) e 36\% (55 DAS).

Apesar de os dados obtidos terem sido ajustados ao modelo quadrático, verifica-se que houve pouca variação entre os valores obtidos nestas doses em comparação com os obtidos nas doses $50 \%$ e $150 \%$, não sendo observado aumento representativo no parâmetro DC quando as mudas foram fertirrigadas com doses acima de $50 \%$ da solução padrão (Figura $2 \mathrm{~B}$ ). $\mathrm{O}$ diâmetro do coleto é considerado uma das mais importantes características para prever a sobrevivência de mudas de várias espécies florestais em campo, tendo também a vantagem de ser facilmente mensurável e de forma não destrutiva (Gomes et al., 2002).
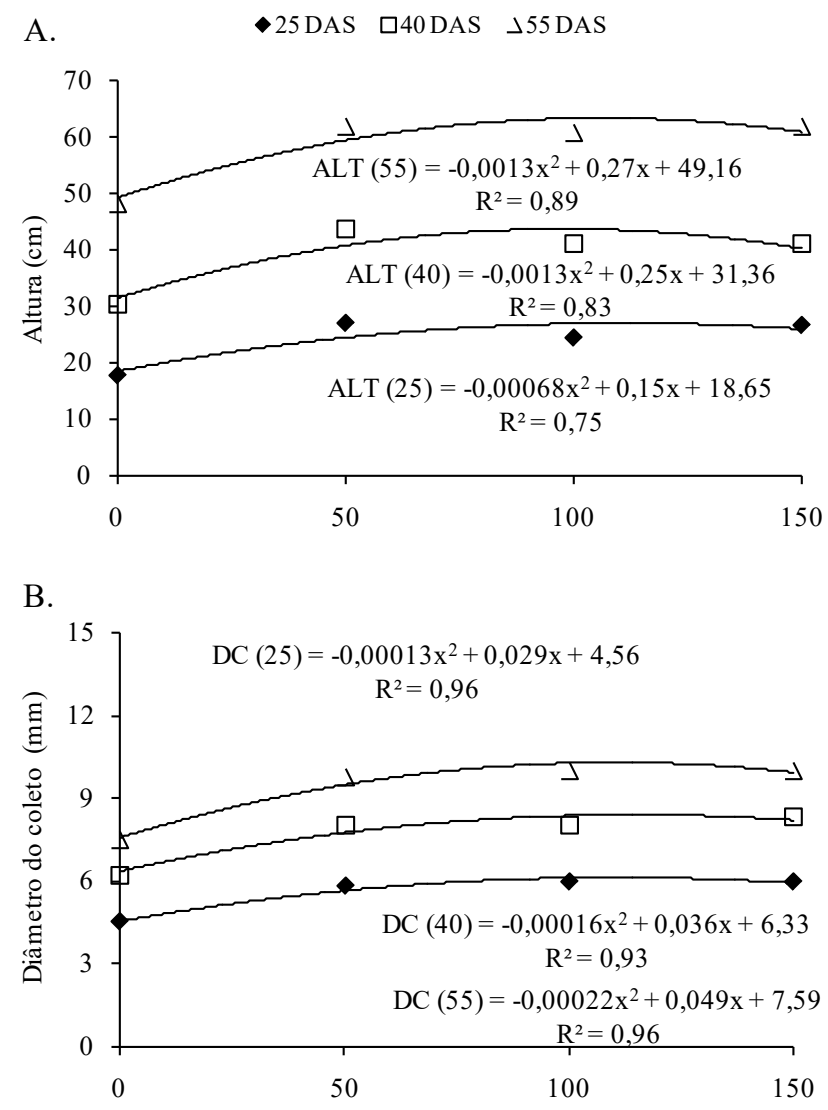

C.

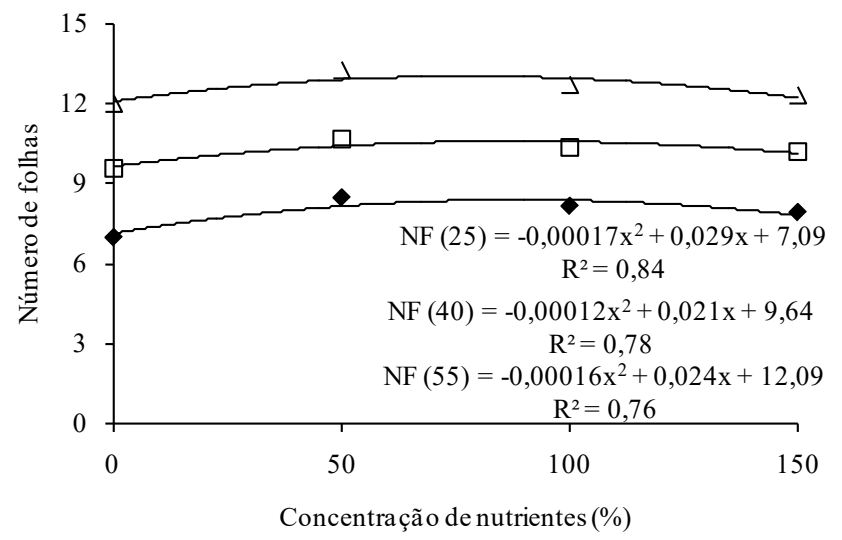

Figura 2. Altura (A), diâmetro do coleto (B) e número de folhas (C) de mudas de moringa (Moringa oleifera Lam.) sob diferentes concentrações de nutrientes na solução de fertirrigação. 
Os maiores valores de NF foram verificados nas concentrações de $85 \%, 87 \%$ e $75 \%$ de fertilizantes, obtendo-se número máximo de 8 (25 DAS), 10 (40 DAS) e 13 (55 DAS). Ao comparar esses valores com os obtidos nas mudas irrigadas apenas com água do sistema de abastecimento, obteve-se aumento de $14,3 \%$ aos 25 DAS, $11,1 \%$ aos 40 DAS e 8,3\% aos 55 DAS. Assim como observado para os parâmetros altura e diâmetro do coleto, verifica-se que houve pouco ganho no número de folhas para doses maiores que $50 \%$ da solução padrão (Figura 2C).

Os dados de matéria seca ajustaram-se em equações quadráticas, e os maiores valores de MSPA $(6,35 \mathrm{~g}$ planta $\left.^{-1}\right), \operatorname{MSSR}\left(2,94\right.$ g planta $\left.^{-1}\right)$ e MST (9,43 g planta $\left.^{-1}\right)$ foram obtidos para as doses referentes a $100 \%, 80 \% \mathrm{e}$ $90 \%$ da solução padrão, respectivamente. Analisando-se o aumento de matéria seca em comparação aos valores obtidos na ausência de fertirrigação, verificaram-se ganhos de $73,9 \%$ para MSPA, $67,3 \%$ para MSSR e $74,1 \%$ para MST (Figura 3).

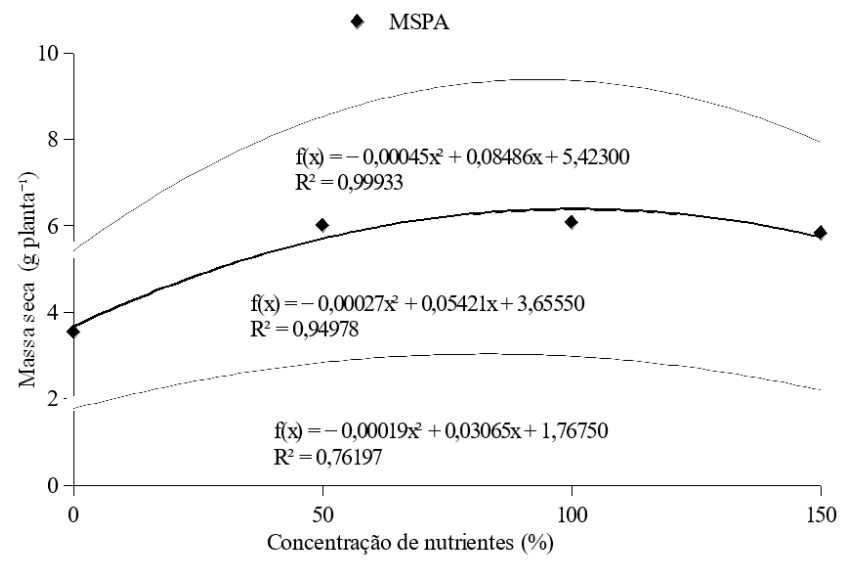

Figura 3. Matéria seca de parte aérea (MSPA), matéria seca do sistema radicular (MSSR) e matéria seca total (MST) em mudas de moringa (Moringa oleifera Lam.) produzidas com diferentes concentrações de nutrientes na solução de fertirrigação

De acordo com os resultados apresentados na Figura 3 , houve maior necessidade de nutrientes para se obter máximo acúmulo de matéria seca na parte aérea $(100 \%)$ em comparação ao sistema radicular (80\%).

Esta resposta ocorreu devido ao padrão de mobilização das reservas e partição dos metabólicos que ocorrem nesta espécie. De acordo com Furtado (2014), a moringa apresenta comportamento diferente de outras espécies arbóreas. Para esta espécie, na fase de plântula ocorre acúmulo de açúcares solúveis totais, açúcares não redutores e aminoácidos livres totais no sistema radicular, enquanto na parte aérea ocorre redução de açúcares solúveis totais e aminoácidos livres totais. Assim, ainda segundo esse autor, essas reservas são consumidas até 20 dias após a embebição das sementes em água destilada, evidenciando a necessidade do suprimento mineral nos primeiros dias após a germinação.

Não houve efeito da posição das sementes no fruto sobre o índice de qualidade de Dickson, obtendo-se valor médio de 1,64. O aumento na concentração de nutrientes na solução de fertirrigação aumentou o valor do índice de qualidade de Dickson até a concentração de $88 \%$ da solução de fertirrigação padrão, obtendo-se IQD de 1,4 (Figura 4A). Souza et al. (2013) verificaram que o IQD em mudas de canafístula aumentou significativamente pelo aumento nas doses de fósforo. Segundo Hunt (1990), o IQD mínimo recomendado é 0,2.

Todos os tratamentos apresentaram IQD acima do índice mínimo necessário, e, conforme Caldeira et al. (2012), quanto maior o IQD, melhor é a qualidade da muda produzida. Entretanto, o uso deste índice deve ser realizado com ressalvas, pois pode variar em função da espécie, do manejo das mudas no viveiro, do tipo e proporção do substrato, do volume do recipiente e, principalmente, de acordo com a idade da muda no momento da avaliação (Gomes et al., 2013).

Para a relação ALT/DC, verificou-se que o aumento na concentração de nutrientes resultou em redução das médias dos parâmetros analisados, obtendo-se a maior relação ALT/DC na concentração $0 \%$ de fertilizante $(6,4)$, enquanto os menores valores ocorreram em soluções variando de $50 \%$ a $75 \%$ da solução de fertirrigação padrão, com ALT/DC de 6,2 (Figura 4B). Esta redução já era esperada, tendo em vista que o aumento na disponibilidade de nutrientes resultou em plantas mais vigorosas.

O uso da fertirrigação com soluções de concentração a partir de $50 \%$ da solução padrão praticamente não resultou em alteração na relação ALT/DC, demonstrando que nessas condições as mudas cresceram de forma estável, tendo em vista que mudas com elevada relação ALT/DC podem ser resultado de crescimento irregular, como em casos de estiolamento. Neste contexto, Carneiro (1995) afirma que a relação ALT/DC exprime um equilíbrio de crescimento, relacionando esses dois importantes parâmetros morfológicos num só índice. 
A

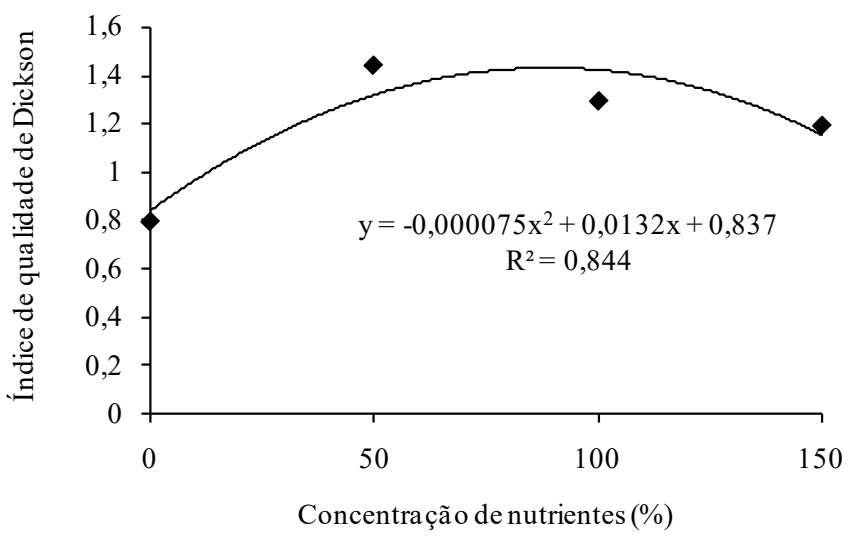

B

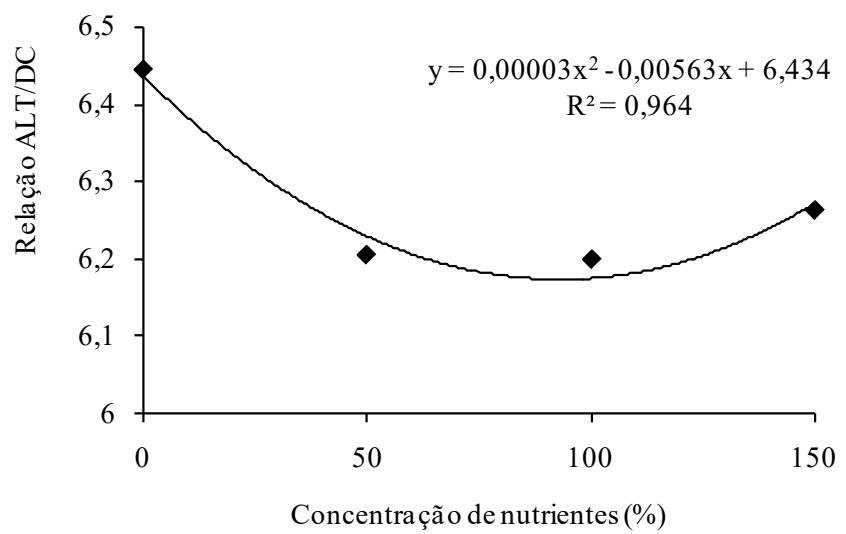

C

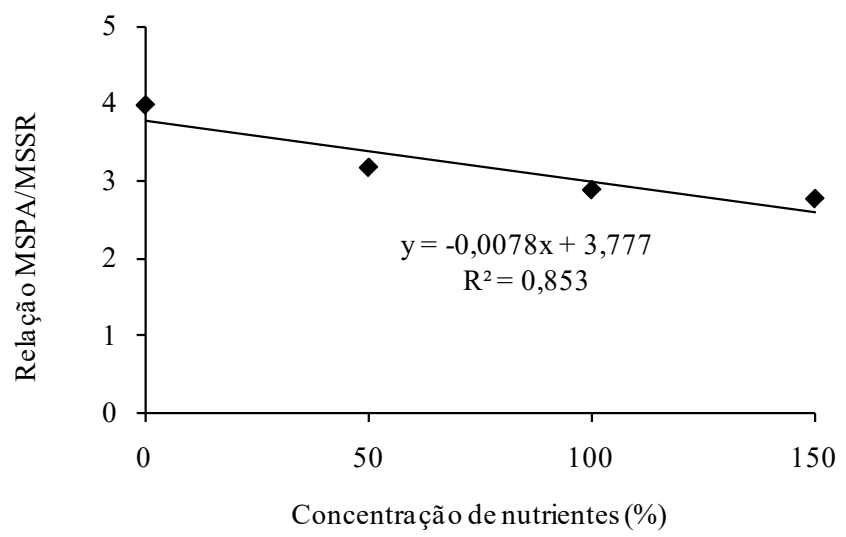

Figura 4. Índice de qualidade de Dickson (A), relação altura/ diâmetro do coleto (B) e relação massa seca da parte aérea/ massa seca do sistema radicular (C) em mudas de moringa (Moringa oleifera Lam.) sob diferentes concentrações de nutrientes da solução de fertirrigação.
De acordo com Gomes et al. (2002), quanto menor o valor obtido na relação ALT/DC, maior será a capacidade de as mudas sobreviverem e se estabelecerem na área de plantio definitivo. Assim, no presente trabalho as mudas fertirrigadas com soluções nas dosagens de 50 e $100 \%$ da solução padrão apresentaram melhor qualidade.

Também houve redução na relação MSPA/MSSR em resposta ao aumento da concentração de nutrientes. As médias enquadraram-se em equação linear decrescente, obtendo-se menores valores na concentração $100 \%$ da solução de fertirrigação padrão $(3,8)$, até obter relação mínima de 2,6 na concentração $150 \%$ da solução de fertirrigação padrão (Figura 4C).

Knapik \& Ângelo (2007), avaliando mudas de pessegueiro produzidas sob quatro tipos de adubação (sem adubação, adubação mineral NPK, adubação mineral NPK acrescida de micronutrientes e pó de basalto), observaram maior acúmulo de matéria seca nas plantas que receberam adubação mineral de NPK acrescida de micronutrientes, e observaram que a parte aérea das mudas é mais afetada que o sistema radicular.

Portanto, o uso de solução nutritiva variando de 80 a $100 \%$ da solução padrão utilizada proporcionou o desenvolvimento de mudas de moringa mais vigorosas, resultados que se assemelham, em parte, aos obtidos por Dantas et al. (2016) em mudas de leucena fertirrigadas por capilaridade, os quais observaram que as melhores foram obtidas entre as concentrações de 70 a $100 \%$ de solução nutritiva via fertirrigação por capilaridade. Também utilizando fertirrigação por capilaridade, em mudas de mulungu, Cavalcante et al. (2016) verificaram que as mudas de melhor qualidade podem ser produzidas utilizando-se fertirrigação com solução nutritiva variando de 70 a $80 \%$ da solução padrão.

\section{Conclusões}

A posição das sementes de moringa nos frutos não afetou o desenvolvimento e o vigor das mudas.

Mudas de moringa de maior qualidade foram produzidas utilizando fertirrigação com solução nutritiva contendo entre 80 e $100 \%$ da solução padrão.

\section{Referências}

Bernardi, A. C. C. et al.. Desenvolvimento de mudas de citrus cultivadas em vaso em resposta à adubação NPK. Scientia Agricola, v. 57, n. 4, p. 733-738, 2000. DOI: 10.1590/S010390162000000400022. 
Caldeira, M. V. W. et al. Biossólido na composição de substrato para a produção de mudas de Tectona grandis. Floresta, v. 42, n. 1, p. 77-84, 2012. DOI: 10.5380/rf.v42i1.26302.

Carneiro, J. G. A. Produção e controle de qualidade de mudas florestais. Curitiba: UFPR/FUPEF, 1995. 451 p.

Cavalcante, A. L. G. et al. Desenvolvimento de mudas de mulungu fertirrigadas com diferentes soluções nutritivas. Floresta, v. 46, n. 1, p. 47-55, 2016. DOI: 10.5380/rf.v46i1.34888.

Claessen, M. E. C. (Org.). Manual de métodos de análises de solo. 2. ed. Rio de Janeiro: EMBRAPA-CNPS, 1997. 212 p. (EMBRAPACNPS. Documentos, 1).

Cruz, C. A. F. et al. Efeito da adubação nitrogenada na produção de mudas de sete-cascas (Samanea inopinata (Harms) Ducke). Revista Árvore, v. 30, n. 4, p. 537-546, 2006. DOI: 10.1590/S010067622006000400006 .

Dantas, R. P. et al. Fertirrigação por capilaridade em mudas de Leucaena leucocephala (Lam.) de Wit. Revista Agro@mbiente Online, v. 10, n. 2, p. 161-167, 2016. DOI: 10.18227/1982-8470ragro. v10i2.3202.

Dickson, A. et al. Quality appraisal of white spruce and white pine seedling stock in nurseries. Forestry Chronicle, v. 36, p. 10-13, 1960.

Ferreira, D. F. Sisvar: a computer statistical analysis system. Ciência e Agrotecnologia, v. 35, n. 6, p. 1039-1042, 2011. DOI: 10.1590/ S1413-70542011000600001.

Ferreira, P. M. P. et al. Moringa oleifera: bioactive compounds and nutritional potential. Revista de Nutrição, v. 21, n. 2, p. 431-437, 2008. DOI: $10.1590 / \mathrm{S} 1415-52732008000400007$.

Freitas, T. P. et al. Morfologia e caracterização da germinação em função da posição das sementes no fruto de sabiá. Scientia Plena, v. 9, n. 3, p. 1-9, 2013.

Furtado, A. L. O. L. Mobilização de reservas e partição de metabólitos durante a germinação da semente e o estabelecimento da plântula em moringa. 2014. 49 f. Dissertação (Mestrado em Ciências Florestal) - Universidade Federal Rio Grande do Norte, Natal.

Gomes, D. R. et al. Lodo de esgoto como substrato para a produção de mudas de Tectona grandis L. Cerne, v. 19, n. 1, p. 123-131, 2013. DOI: $10.1590 / \mathrm{S} 0104-77602013000100015$.

Gomes, J. M. et al. Parâmetros morfológicos na avaliação da qualidade de mudas de Eucalyptus grandis. Revista Árvore, v. 26, n. 6, p .655-664, 2002. DOI: 10.1590/S0100-67622002000600002.

Jesus, A. R. et al. Cultivo da Moringa oleifera. Brasília, DF: Instituto EuvaldoLodi; Salvador: IEL, 2013. 23 p. (Dossiê técnico).
Hunt, G. A. Effect of styroblock design and cooper treatment on morphology of conifer seedlings. In: TARGET SEEDLING SYMPOSIUM, MEETING OF THE WESTERN FOREST NURSERY ASSOCIATIONS, GENERAL TECHNICAL REPORT RM-200, 1990, Roseburg. Proceedings... Fort Collins: United States Departament of Agriculture, Forest Service, 1990. p. 218-222.

Knapik, J. G. \& Ângelo, A. C. Crescimento de mudas de Prunus sellowii Koehne em resposta a adubações com NPK e pó de basalto. Floresta, v. 37, n. 2, p. 257-264, 2007. DOI: 10.5380/rf.v37i2.8655.

Lo Monaco, P. A. V. et al. Efeito da adição de diferentes substâncias químicas no extrato de sementes de moringa utilizado como coagulante no tratamento de esgoto sanitário. Engenharia Agrícola, v. 34, n. 5, p. 1038-1048, 2013. DOI: 10.1590/S010069162013000500015.

Marcos Filho, J. Fisiologia de sementes de plantas cultivadas. Piracicaba: FEALQ, 2005. 495 p.

Oliveira, O. F. \& Morais, P. L. D. Influência da posição da semente (no fruto) na germinação e no desenvolvimento vegetativo inicial de leucena (Leucaena leucicephala (Lam.) de Wit) e algarobeira (Prosopis juliflora (SW.) DC. Revista Caatinga, v. 10, n. 1/2, p. 55-62, 1997.

Oliveira, F. A. et al. Crescimento de mudas de moringa em função da salinidade da água e da posição das sementes nos frutos. Revista Árvore, v. 37, n. 1, p. 79-87, 2013. DOI: 10.1590/S010067622013000100009 .

Pritchard, M. et al. A comparison between Moringa oleifera and chemical coagulants in the purification of drinking water-An alternative sustainable solution for developing countries. Physics and Chemistry of the Earth, v. 35, p. 798-805, 2010. DOI: 10.1016/j. pce.2010.07.014.

Sánchez-Martín, J. et al. Comparison of single-step and two-step purified coagulants from Moringa oleifera seed for turbidity and DOC removal. Bioresource Technology, v. 101, p. 6259-6261, 2010. DOI: 10.1016/j.biortech.2010.02.072.

Sarzi, I. et al. Características biométricas de mudas de Tabebula chrysotricha (standl.) formadas em diferentes substratos e soluções de fertirrigação, quando plantadas em campo. Revista Árvore, v. 34, n. 2, p. 241-149, 2010. DOI: 10.1590/S0100-67622010000200006.

Souza, N. H. et al. Estudo nutricional da canafístula (I): crescimento e qualidade de mudas em resposta à adubação com nitrogênio e fósforo. Revista Árvore, v. 37, n. 4, p. 717-724, 2013. DOI: 10.1590/ S0100-67622013000400015.

Tucci, C. A. F. et al. Desenvolvimento de mudas de Swietenia macrophylla em resposta a nitrogênio, fósforo e potássio. Floresta, v. 41, n. 3, p. 471-490, 2011. DOI: 10.5380/rf.v41i3.24039. 